\title{
Diagnosis and management of obstetric cerebral venous thrombosis: a stringent challenge
}

\author{
Sheeba Marwah ${ }^{1}$, Ritin Mohindra ${ }^{2}$ \\ ${ }^{1}$ Department of Obstetrics and Gynecology, VMMC and Safdarjung Hospital, New Delhi 110029, India \\ ${ }^{2}$ Department of Medicine, VMMC and Safdarjung Hospital, New Delhi 110029, India
}

Received: 23 October 2016

Accepted: 20 November 2016

\section{*Correspondence:}

Dr. Sheeba Marwah,

E-mail: sheebamarwah@yahoo.co.in

Copyright: ( ) the author(s), publisher and licensee Medip Academy. This is an open-access article distributed under the terms of the Creative Commons Attribution Non-Commercial License, which permits unrestricted non-commercial use, distribution, and reproduction in any medium, provided the original work is properly cited.

\begin{abstract}
Cerebral venous thrombosis is an uncommon but serious neurologic disorder in young adults with a peculiarly high preponderance for females. Diagnosis is frequently overlooked or deferred due to its subacute or lingering onset and the wide spectrum of clinical symptoms. Headache is the most frequent symptom occurring in up to $95 \%$ of all cases. One must consider stroke in all cases of neurological deterioration in pregnancy and puerperium. Imaging plays a primary role in diagnosis with magnetic resonance imaging (MRI) and magnetic resonance angiography (MRA) having proven to be the best both for diagnosis and follow-up of these women. Current therapeutic measures used include the utilization of anticoagulants such as dose-adjusted intravenous heparin or body weight adjusted subcutaneous low-molecular-weight heparin (LMWH), the use of thrombolysis and symptomatic therapy including control of seizures and elevated intracranial pressure. Recurrence in future pregnancy is usually low.
\end{abstract}

Keywords: Cerebral venous thrombosis, Management, Pregnancy, Puerperium, Stroke

\section{INTRODUCTION}

Thrombosis of cerebral veins and sinuses is a distinct stroke, mostly afflicting young middle aged population with female to male ratio being $3: 1 .{ }^{1}$ It is responsible for $0.5 \%$ of all stroke cases in developed countries, whereas in developing realms like India it contributes $10-17 \%$ of all cases. ${ }^{2,3}$ Pregnancy and puerperium account for $20 \%$ of CVT cases in Indian population accounting for $4.5 / 1000$ obstetric admissions and 1/250 deliveries. ${ }^{2,4}$ In the pre-antibiotic era post-infective CVT was more prevalent, whereas nowadays aseptic CVT is more frequent. $^{5}$ The precise incidence of this ailment is not known because of dearth of available scientifically intended epidemiological studies in the literature. However its prevalence is much less when contrasted with arterial stroke.

\section{ETIOLOGY}

More than 100 causes of CVT have been expounded in literature. ${ }^{2,4-6}$ However, despite of extensive investigations, the cause may be elusive in up to $20-25 \%$ of patients. ${ }^{6}$ Currently, infective causes account for less than $10 \%$ of patients, while inherited pro-thrombotic tendencies account for $10-15 \%$ of cases. ${ }^{2,7}$ Pregnancy and puerperium have long been recognized as periods of increased susceptibility. ${ }^{7-11}$ Significantly increased risk has been associated with caesarean delivery, increased maternal age, hyperemesis, inter-current infection and maternal hypertension. Increased risk during pregnancy and puerperium is due to a hypercoagulable state caused by increased levels of fibrinogen, Factors VII, VIII and $\mathrm{X}$, Diminution in inhibitors of Protein $\mathrm{S}$ coagulant, Increase in inhibitors of Protein $\mathrm{C}$ level, increased ability to neutralize Heparin. ${ }^{10-14}$ Also oral contraceptive pills 
use has been associated with an increased pro-thrombotic tendency in females of reproductive age group. ${ }^{15}$

\section{PATHOGENESIS}

CVT ensues occlusion of venous sinus by a partially obstructing thrombus or an extrinsic compression that ultimately progresses to completely impede it. The thrombus may further extend into the draining veins of the sinus. The resulting venous congestion leads to regional ischemia and infarction in cerebral cortex.

\section{CLINICAL FEATURES}

Most frequent symptoms and signs in CVT in pregnancy and puerperium are headache $(75-95 \%)$, focal seizure with/without generalization, paresis (unilateral or bilateral), papilledema, altered mental status, isolated intracranial hypertension, diffuse encephalopathy and CT/MRI findings of focal edema/ infarct/ hemorrhage. ${ }^{1,3,5,8,16}$ Rarely it can cause cavernous sinus syndrome, subarachnoid hemorrhage, thunder clap headache or attacks of migraine with aura.

\section{Sagittal sinus thrombosis}

Focal neurological deficit comprises of hemiparesis, usually with facial sparing and more severe affection of lower limbs than upper limbs. ${ }^{15-18}$ In some patients, contra-lateral cortical veins may be involved resulting in paresis/paralysis of the opposite lower limb thus causing paraparesis/paraplegia. ${ }^{19,20}$

\section{Cavernous sinus thrombosis (usually septic)}

Fever, headache, frontal and retro-orbital pain and diplopia are common symptoms. Ptosis, proptosis, chemosis, extra-ocular dysmotility and hyperesthesia of ophthalmic and maxillary division of $\mathrm{V}$ cranial nerve are common signs. Compression of optic nerve may lead to optic atrophy and blindness.

Lateral sinus thrombosis-It is mostly secondary to infections of middle ear and mastoid region. Headache and earache are the most common symptoms.

\section{Thrombosis of deep cerebral veins}

It is usually accompanied by LOC and occasional abnormalities of eye movements or papillary reaction.

\section{COMPLICATIONS}

Increased dural sinus and CSF pressure, Parenchymal edema with venous infarction or hemorrhage, pulmonary embolism from dural sinus thrombosis, Hypopituitarism from cavernous sinus thrombosis, persistence of focal seizures. $^{21-24}$

\section{DIAGNOSIS}

Timely diagnosis of CVT Requires "high index of suspicion".

\section{Blood investigations}

Complete blood count for polycythemia, thrombocytopenia (TTP), leucocytosis (sepsis), anti phospholipid antibodies, protein $\mathrm{C}$ and $\mathrm{S}$, anti thrombin III, lupus anticoagulant and leiden factor $\mathrm{V}$ mutation for hypercoagulable states, blood for homocysteine levels (easily correctable), ESR and ANA for screening of SLE, Wegner's granulomatosis, Urine protein for nephritic syndrome, liver function test for cirrhosis of liver.

\section{Imaging techniques}

MRI brain and Venography is the investigation of choice and shows absent flow void within affected venous sinuses. $^{25}$ Unenhanced time of flight MRV, Contrastenhanced MRV, Fluid-attenuated inversion recovery (FLAIR) and $\mathrm{T} 2 *$ Gradient- echo imaging assist in clinching diagnosis.

CT scan-On non-contrast CT, the classic finding in delta sign (observed as a dense triangle within the superior sagittal sinus created by hyperdense thrombus). A false positive delta sign may be seen in trauma patients as a result of an adjacent sub-dural hematoma. ${ }^{26}$ On contrast enhanced CT, the reverse delta sign (empty delta triangle sign) can be observed in superior sagittal sinus from enhancement of dural leaves surrounding the comparatively less dense thrombosed sinus $(20 \%$ of the cases). ${ }^{27}$ False negative rate for diagnosing by CT is $25 \%{ }^{7}$ Other abnormalities seen on CT are Cerebral edema, Hemorrhagic infarction and inter-cerebral hemorrhage, Cord sign(irregular and high-density lesion located in superficial aspect of cerebral hemisphere represents thrombosed cortical veins).

Recently, CT venography has been shown to have sensitivity equal to or superior to MR Venography in visualizing thrombosed sinuses. However it is not used routinely.

Cerebral angiography being an invasive technique, nonsensitive, non-specific technique for CVT, is obsolete now. $^{28}$

Radionuclide scanning also because of lack of specificity has entered the antique list. ${ }^{29}$

\section{Other investigations}

a) Lumbar puncture- Though it does not offer much assistance in establishing diagnosis, but abnormalities encountered in Lumbar Puncture are raised pressure, pleocytosis, increased RBCs, elevated CSF protein. ${ }^{30}$ 
b) D-dimer- It's a marker of endogenous Fibrinolysis, and is positive in $77 \%$ pts with CVT. Negative Ddimer assay cannot rule out CVT.

\section{TREATMENT}

a) Symptomatic treatment-Woman with hemiplegia should be kept nil by mouth to prevent aspiration. Normal saline is recommended at the rate of 1 liter in 24 hours. Head elevation is done at 30-40 degrees to decrease intracranial tension. Besides Lumbar puncture, Acetazolamide and Surgical procedures can be opted for. Seizures should be treated with appropriate anticonvulsants. Classical antiepileptic drugs like phenytoin, carbamezepine, and valproate should be chosen. In case of intolerance to classic drugs, newer antiepileptics like lamotrigine, topiramate and levetiracetam should be resorted to.

b) Impairment of consciousness or herniation can be managed with Osmotic therapy, Sedation and ventilation, and if required hemi-craniotomy. In infected CVT, appropriate antibiotics should be given.

c) Specific therapy.

\section{Acute phase}

Body-weighted LMW heparin in full therapeutic dosage or dose adjusted IV heparin until 13 weeks followed by Warfarin up to $3^{\text {rd }}$ trimester; again UFH/LMWH is reinstituted till delivery and is continued till 6 weeks postpartum.

i) Unfractionated Heparin at a loading dose of 80units/kg-body weight followed by initial infusion at the rate of 18 unit/ $\mathrm{kg} /$ hour should be started and APTT checked 6 hourly. If APTT is less than 1.2 times the control another bolus and increase in Heparin to 40 units/kg/hour. If APTT is $1.5-2.3$ times the control no change in infusion rates is done. If APTT is 2.3-3 times the control, infusion rates must be decreased by 2 units/ kg/ hour. If APTT is $>3$ times the control, the infusion should be held for one hour and rate decreased by 3 units $/ \mathrm{kg} /$ hour.

ii) Low molecular weight heparin in dose of $1 \mathrm{mg} / \mathrm{kg}$ body weight subcutaneous twice a day.

iii) Warfarin - Start with $5 \mathrm{mg}$ once in a day dose and maintain PT with INR between 2 and 3.

\section{Worsening despite medical treatment}

Failure to respond to therapy is usually suggested by deepening coma or worsening neurological deficit in spite of adequate heparinisation.

i) Local IV thrombolysis with rtPA streptokinase (SK) or urokinase (UK) via selective catheterization of cerebral veins

ii) Mechanical thrombectomy iii) No controlled data for use of steroids or decompressive surgery.

However heparin still remains first line treatment for CVT because of its efficacy, safety and feasibility. ${ }^{32}$

\section{Maintenance therapy}

a) Oral Anti coagulation continued till 3 months if transient risk factor present; in case of Idiopathic CVT and mild hereditary thrombophilia, it can be continued up to 6-12 months. If two or more episodes of CVT or one episode of CVT with severe hereditary thrombophilia is documented, woman requires infinite anticoagulation.

b) Antiepileptic therapy should be continued for minimum 1 year in case of early seizures and hemorrhagic lesions. In woman without risk factors, one must taper gradually after acute stage.

\section{PROGNOSIS OF Obstetric CVT}

With the advent of early diagnosis and early institution of therapy mortality in CVT has been reduced from $50.6 \%$ to $10 \%$ in last three decades. ${ }^{33,34}$ Poor Prognostic markers are age $>33$ yrs, acute fulminant course, papilledema, coma, B/L hemorrhagic infarctions, diffuse cerebral edema, involvement of straight sinus. Recurrence risk in successive pregnancies is Low (2\%). Overall it carries favourable outcome in $60-76 \%$ cases. Moreover there is no contraindication to future pregnancies. Further investigations regarding the underlying cause and a formal consultation with a haematologist and/or maternal foetal medicine specialist are reasonable.

\section{ACKNOWLEDGEMENTS}

We cannot reimburse in words and in deed, adoration and gratefulness to all our patients suffering from cerebral venous thrombosis we came in contact with, for their contribution towards making this review reach a successful culmination. We hereby pay our sublime observance and convivial gratitude to all of them, besides wishing them a swift recovery.

Funding: No funding sources Conflict of interest: None declared

Ethical approval: Not required

\section{REFERENCES}

1. Bushnell C, Saposnik G. Evaluation and management of cerebral venous thrombosis. Continuum (Minneap Minn), Cerebrovascular Disease. 2014;20(2):335-51.

2. Shah M, Agarwal N, Gala NB, Prestigiacomo CJ, Gandhi CD. Management of Dural Venous Sinus Thrombosis in Pregnancy; 2014.

3. Bousser MG, Ferro JM. Cerebral venous thrombosis: an update. Lancet Neurology. 2007;6(2):162-70. 
4. Bansal BC, Prakash C. CVT. J of Indian Academy of Clinical Medicine. 1999;5(1):55.

5. Guenther G, Arauz A. Cerebral venous thrombosis: a diagnostic and treatment update. Neurologia (Barc Spain). 2011;26(8):488-98.

6. Kalbag RM, Wolf AL. Etiology of cerebral venous thrombosis. Cerebral venous thrombosis. Kalbag RM, Wolf AL. Oxford University Press London; 1967:238.

7. Ameri A, Bousser MG. CVT. Neurol Clin. 1992;10:87-111.

8. Deschuins M, Conrad J, Korellon M, Amri A, Preter M, Chidu F. Coagulation studies, Factor V Leiden and anticardiolipin antibodies in forty cases of CVST. Stroke. 1996;27:1724-30.

9. Cole B, Criddle LM. A case of postpartum cerebral venous thrombosis. J Neurosci Nurs. 2006;38(5):350-3.

10. Nazziola E, Elkind MS. Dural sinus thrombosis presenting three months postpartum. Ann Emerg Med. 2003;42(4):592-5.

11. Martin J, Sheehan H. Primary thrombosis of cerebral veins. BMJ. 1941;1:349-53.

12. Conn C, Bairnaganemanteria F. CVT associated with pregnancy and puerperium: A review of sixty seven cases. Stroke. 1993;24:1880-4.

13. Saposnik G, Barinagarrementeria F, Brown RD, Bushnell CD, Cucchiara B, Cushman M, et al. Diagnosis and management of cerebral venous thrombosis: a statement for healthcare professionals from the American Heart Association/American Stroke Association. Stroke. 2011;42(4):1158e92.

14. Treadwell SD, Thanvi B, Robinson TG. Stroke in pregnancy and the puerperium. Postgrad Med J. 2008;84(991):238e45.

15. Maitinelli I, Sacchi E, Landi G. High risk of CVT in carriers of prothrombotic gene mutation and users of OCPs. N Engl J Med. 1988;338:1793-7.

16. De Bruijin SF, De Haan R, Stam J. Clinical features and prognostic factors of CVST in a prospective series of fifty-nine patients. J Neurol Neurosurg Psychiat. 2001;70:105-8.

17. Daif A, Awade A, Al-Rajeh A. Malibury cerebral venous thrombosis in adults a study of forty cases. Stroke. 1995;26:1193-5.

18. Panagiotis Zis, Tavernarakis A. Headache and Status Epilepticus in the Postpartum Period; Posterior Reversible Encephalopathy Syndrome or Cerebral Venous Thrombosis? Case Reports in Emergency Medicine, Article ID 680327; 2013:3.

19. Prakash C, Singh S. Cerebral venous thrombosis in puerperium. J Assoc Phys India. 1960;8:363-5.

20. Janki S, Thomas L. Neurological complications in pregnancy and puerperium. Neurology India. 1963;11:128-30.
21. Hayley EC, Brashear HM, Barth JT, Cail WS, Kassel N. Deep cerebral venous thrombosis: Clincal, neuroradiological and neuropsychological correlates. Arch Neurol. 1989;46:337-40.

22. Witterdink L, Eaton J. CVT. Cerebral ischaemia. In Neurology i.e. complication of pregnancy. Eds. Daminsky O, Friedman E, Hainline B. Raven press NY; 1994:1-23.

23. Tanya N. Turan, Barne JY. Stern Stroke in pregnancy Ed Page B Pennel. Neurologic clinics, New Delhi Elsevier. 2004:821-840.

24. Sarella LK, Rao DS. Neurological Disorders in Pregnancy and Puerperium. Sri Lanka Journal of Obstetrics and Gynecology. 2014:74-8.

25. Shih-jung Cheng, Pei-hao Chen, Luan Chen, Chihping Chen. Stroke during pregnancy and puerperium: clinical perspectives. Taiwan Journal of obstetrics and gynecology. 2010;49(4):395-400.

26. Nagaraja D, Rao Bss, Taly AB, Subhash MN. Randomized controlled trial of heparin in puerperal cerebral venous/sinus thrombosis. Nimhans J. 1995;13:111-5.

27. Ramenghi LA, Gill BJ, Tanner SF, Martinez D, Arthur R, Levine MI. Cerebral venous thrombosis, intraventricular hemorrhage and white matter lesions in a preterm newborn with Factor $\mathrm{V}$ mutation. Neuropaediatrics. 2002;33:97-9.

28. Bannus BD, Winestock DK. Dynamic radionuclide scanning in diagnosis of thrombosis of superior sagittal sinus. Neurology. 1977;27:656.

29. Patel MR. Brain, venous sinus thrombosis, 2002. [Cited 2003 May 17]. Available at: http://www.emedicine.com/radio/topic105.htm.

30. Bousser MG, Chinas J, Bories J, Cartegne P. CVT: A series of thirty eight cases. Stroke. 1985;16:199-213.

31. Einhaupla K, Stamb J, Bousserc MG, de Bruijnd SFTM, Ferroe JM, Martinellif I, et al. EFNS guideline on the treatment of cerebral venous and sinus thrombosis in adult patients. European Journal of Neurology. 2010;17:1229-35.

32. Bousser MG. Cerebral venous thrombosis: nothing, heparin, or local thrombolysis? Stroke. 1999;30:4813.

33. Ferro JM, Canhao P, Stam J, Bousser MG, Barinagarrementeria F. Prognosis of cerebral vein and dural sinus thrombosis: results of the International Study on Cerebral Vein and Dural Sinus Thrombosis (ISCVT). Stroke. 2004;35:664-70.

34. Srinivasan K. Stroke in young. Neurology India. 1988;36:189-94.

Cite this article as: Marwah S, Mohindra R. Diagnosis and management of obstetric cerebral venous thrombosis: a stringent challenge. Int $\mathrm{J}$ Reprod Contracept Obstet Gynecol 2016;5:4095-8. 